\title{
Commentary: Arteries and veins: Choices abound
}

\author{
Joseph C. Cleveland, Jr, MD
}

\author{
From the Division of Cardiothoracic Surgery, University of Colorado Anschutz Medical Center, Aurora, Colo. \\ Disclosures: Author has nothing to disclose with regard to commercial support. \\ Received for publication Jan 8, 2019; accepted for publication Jan 9, 2019; available ahead of print March 7, 2019. \\ Address for reprints: Joseph C. Cleveland, Jr, MD, Fred and Carol Grover Endowed Chair in Surgery, Academic \\ Office 1, 12631 E. 17th Ave, Room 6602 Aurora, CO 80045 (E-mail: joseph.Cleveland@ucdenver.edu). \\ J Thorac Cardiovasc Surg 2019;158:154 \\ $0022-5223 / \$ 36.00$ \\ Copyright (c) 2019 by The American Association for Thoracic Surgery \\ https://doi.org/10.1016/j.jtcvs.2019.01.032
}

The evolution of coronary artery bypass grafting (CABG) surgery continues. Whether to conduct the operation onpump or off-pump continues as an active debate. ${ }^{1,2}$ The choice of conduits-whether arterial or venous-remains a highly investigated and active area of clinical research. ${ }^{3}$ For good reason, cardiothoracic surgeons do not remain static. The desire that resides within all of us who perform CABG to improve the operation is robust.

Witness the manuscript published in this issue of the Journal by Formica and colleagues. ${ }^{4}$ They explore whether adding a radial artery or a saphenous vein as the third conduit during $\mathrm{CABG}$ with bilateral internal mammary (BIMA) yields a clear winner. The short answer is that long-term survival is identical for patients who undergo CABG with BIMA and either a radial artery or a saphenous vein as the third conduit. Strengths of this manuscript include the use of a propensity score to mitigate confounding issues in these 2 retrospective patient cohorts. The limitations include that the patient groups were small, and this is study is a single-center, retrospective study. However, the authors are to be commended for achieving outstanding long-term results with both cohorts-survival exceeding $75 \%$ in both groups at 15 years. To date, the use of the radial artery as a conduit is still below $15 \%$ in most large studies.

In my opinion, the results of this study likely relate to the strong protective effect that revascularization with BIMA exerts on a young population (average age 60 years). Stated differently, the use of BIMA dominated what additional benefit may or may not exist with use of a radial artery versus a saphenous vein for the third target vessel that was revascularized. The other very strong message in this manuscript speaks to the long-term survival afforded by CABG. Lastly, isn't it great that for those surgeons who have developed a strong affinity for the radial artery - that they can use this conduit with BIMA? Similarly, the workhorse of $\mathrm{CABG}$ - the reliable saphenous vein-stands up We have a choice!

\section{References}

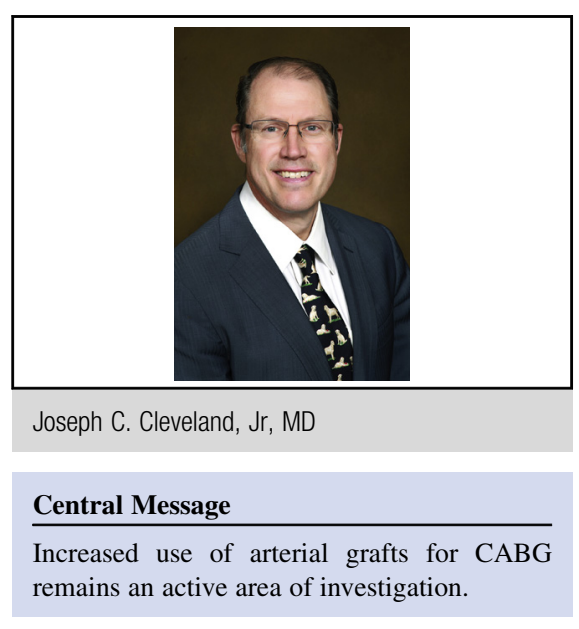

See Article page 141.

equally to the radial artery for those who prefer to use veins.

In summary, I think many surgeons have considered a variety of strategies to optimize revascularization with arteries and veins. I paraphrase what other cardiac surgeons have previously stated, "Tailor the operation to the patient." 6 We are indeed fortunate to have choices and a fantastic platform-CABG-on which to build the appropriate operation for each patient.

1. Shroyer AL, Hattler B, Grover FL. Five-year outcomes after on-pump and off-pump coronary-artery bypass. N Engl J Med. 2017;377:623-32.

2. Chikwe J, Lee T, Itagaki S, Adams DH, Egorova E. Long-term outcomes after off-pump versus on-pump coronary artery bypass grafting by experienced surgeons. J Am Coll Cardiol. 2018;72:1478-86.

3. Rocha RV, Tam DY, Karkhanis R, Nedadur R, Fang J, Tu JV, et al. Multiple arterial grafting is associated with better outcomes for coronary artery bypass grafting patients. Circulation. 2018;138:2081-90.

4. Formica F, D’Alessandro SD, Singh G, Ciobanu AM, Messina LA, Scianna S, et al. The impact on late survival of the radial artery or the saphenous vein in addition to the bilateral internal mammary arteries. A propensity analysis. $J$ Thorac Cardiovasc Surg. 2019;158:141-51.

5. Iribane A, Goodney PP, Flores AM, DeSimone J, DiScipio AW, Austin A, et al. National trends and geographic variation in bilateral internal mammary artery use in the United States. Ann Thorac Surg. 2017;104:1902-7.

6. Bakaeen FG, Sabik JF III. Tailoring operations to the patient is always best. Circulation. 2016;134:1221-3. 